\title{
On Relations between Individuals and Groups in the Process of the Social Transformation of Contemporary China
}

\author{
Hongbo Wang ${ }^{1, a}$, Ying $\mathrm{Li}^{2,}$ b \\ ${ }^{1}$ School of Marxism, Capital Normal University, Beijing 100048, China \\ ${ }^{2}$ School of Humanities and Law, North China University of Technology, Beijing 100144, China \\ awhb7663@126.com, bliying63nk@126.com
}

Keywords: individual, group, subjectivity, relations, contemporary china, social transformation.

\begin{abstract}
In the practical Chinese society, The subjectivity of individual and group is in the process of transformation. In this situation, around relations of individual and group, we should focus on the following problems: firstly, cultivation and generation of the subjectivity of individual and group; secondly, cultural choice and system innovation. thinking and responding deeply to the above Several aspects will contribute to construct a kind of interactive mechanism between individual and group.
\end{abstract}

\section{Introduction}

Now in China, people's mode of production, lifestyles and ways of thinking are experiencing unprecedented changes. Chinese society is in a process of institutional transformation and structural change. In the process, there are mainly two pairs of relationships: tradition and modernization, individuals and groups. Traditional society is based on community affiliation while individual values is outstanding in modern society. Therefore, individual-community relationship comes to the core of tradition-modernization relationship. Thus, individual-community relationship is the focus of this dissertation, which also needs to be interpreted in theory and to be resolved in practice.

\section{The subjective transformation and perplexity of individuals and groups}

Objectively, what is missing in traditional Chinese society is not only individual subjectivity, but also community subjectivity. Individual subjectivity in contemporary China has become prominent; undoubtedly, the main reason is market-orientated economic activity. Under the influence of market orientation, individual activities gradually go beyond the range of family and social organizations. Market has become a director to personal economic activities; from an objective perspective, autonomous individuals are required in reality.

Arguably, corresponding to social transformation in contemporary China, individual subjectivity is also in a process of transformation. The two subjective statues self-loss and self-consciousness are interwoven in a complicated way in individuals. Sometimes one of them dominate, sometimes they coexist. But, we cannot exclude that some individuals go ahead or behind those two phases. However, because of this situation, subjectivity differences among individuals can be prominent in social transformation; and it can provide us with possible clues to describe the evolution progress and regular pattern of individual subjectivity.

Community subjectivity is also gradually established in the relationship with the object that it is facing to. Due to subjective differences among the individuals which compose a community, subjectivity of different communities also has difference. During the transformation of contemporary China, corresponding to transformation process of individual subjectivity, community subjectivity is in a process of transformation too. Generally speaking, community subjectivity formed later than individual subjectivity. Because individual subjectivity formation is the premise and foundation of community subjectivity; community subjectivity depends on inter-subjectivity of community members with subjectivity; the whole system is made up by members within the community, and various individuals are willing to dialogue and exchange on an equal basis. 
Subjectivity is one of the important concepts deeply rooting in modern people's spirit world. But when we tried to use subjectivity for realization of the outside world, namely, when subjectivity is combined with real life, contradictions and conflicts occurred. This may be more prominent in contemporary China (individual and community are in a process of social transformation). Such contradictions and conflicts is confusion or worry of the subjectivity. Subjectivity confusion of contemporary Chinese individuals and communities roughly manifested as follows: economically, Chinese society is in a transition process from pre-market-economy to market-economy; politically, it is in a historical transition stage from a totalitarian political system to a democratic political system; in ideology and culture, it is in a transition from traditional culture to modern culture.

Corresponding to the changes of the three areas of the transformation society, The "subjective perplexity" of the individual and group in contemporary China is shown as follows.

In the economic field, Chinese society is in the process of transition from pre-market economy to market economy. In this transition period, on the one hand, The market economy has greatly promoted the progress of individuals and society, but at the same time, in the process of transformation of the old and new economic system, there must be many institutional deficiencies and defects. Inevitably, Men having the power's resources utilize these shortcomings and defects to "hit edge ball of policy" or "drill loopholes of laws"(Yao Huai. L, 1997)under the driving of benefit mechanism. In this case, The main body of the market economy (individual and group, etc.) only has the equality of formal meaning rather than the true equality, accordingly, The real body of the market economy also partially lost its subjectivity, This confusion can be regarded as the confusion of subjectivity in the economic field.

In the political field, Chinese society is in the transition from centralized political system to democratic political system. In the transition period, to some extent, The political power structure will inevitably produce fission and reorganization, so power and interest relations will be unusually prominent. Moreover, Because effective and sound political and legal system and supervision mechanism that is needed in the transition society has not been fully established, The inevitable result is that there are lots of "power rent-seeking" and other social corruption in social life. In this case, The individuals and groups that should be the subject often feel incapable of actions in the social life of many things, and express a helpless feeling. This confusion is the the confusion of subjectivity in the field of political.

In the field of ideology and culture, Chinese society is in the transition from traditional culture to modern culture. Here "modern culture" mainly includes such cultural factors: Chinese traditional culture, Western culture, Marxism's culture and other world cultures, etc. In the current Chinese society, The above-mentioned cultural factors are in conflict and mutual infiltration of contradictions, so China's "modern culture" is a kind of cultural state to be completed. In contemporary China, In theory and practice, there is a heated debate on how to build a new type of modern culture. Therefore, the realistic individuals and groups are in a multi-cultural interwoven, promiscuous network of culture. The individuals and groups are surrounded by a variety of cultural state, impact and dip, It is difficult to select and define by self ,and it is difficult to form a certain universal or public cultural identity. Therefore, The subjectivity of individuals and groups will not inevitably be established, and will inevitably produce realistic cultural choice or cultural identity confusion. This kind of realistic perplexity is the subjectivity confusion in the field of ideology and culture.

\section{Building relations between personal and social relationships}

Facing the reality of social transformation, focusing on the relationship between individuals and communities, cultivation and generation of individual and community subjectivity, cultural selection and system innovation need to be deeply researched. Deep thinking and answer to those two questions will help to find possible ways to construct a favorable interaction mechanism between individuals and communities. 


\subsection{Cultivation and generation of individual and community subjectivity}

Community subjectivity goes beyond individual subjectivity; it's the coagulation and sublimation of much individual subjectivity. Theoretically and practically, before the cultivation and generation of individual and community subjectivity, we should strive to think and solve the following two questions: First, social reality support is required for cultivation and generation. Namely, with the development of social transformation, sense of confusing and losing from socio-economic, political and cultural aspects of individuals and communities should be gradually eliminated; so that individuals and communities can truly become a real existence with real subjectivity; that is an essential prerequisite of cultivation and generation. Second, correctly handling the dialectic relationship between individual subjectivity and community subjectivity is quite important. Individual subjectivity is the premise and foundation of community subjectivity and it's the ultimate aim of community subjectivity construction and realization.

Some Chinese scholars argue that in the context of modernization and market economy, choices are fundamentally made by individuals although in the meantime they are being made by communities and groups, which nevertheless end in personal choice. Admittedly, one can make choices for others to some extent. Yet this possibility diminishes with the development of market economy under which the interpersonal relations are equal and independent. Meanwhile, in a democratic society, the common choice on public affairs often lies in individuals.

Apparently, this statement explains what subjectivity is from the perspective of choice. As China's market economy and democracy develop, or the social transformation speeds up, the choice and subjectivity of individuals outweigh those of groups which are eventually actualized by the former. In addition, only when individuals truly gain their subjectivity can the groups demonstrate true group subjectivity or common subjectivity on the basis of adequate individual communication. The subjectivity of groups is crucial and essential assurance to its actualization at individual level. Because the subject of groups subjectivity is a transpersonal existence, it forms from individual subjectivity. However, the subjectivity of groups once comes into being, its power is greater than individual subjectivity. In the manner of group subjectivity, communicating and interacting with other groups could form group intersubjectivity. The results of communicating and interacting among group subjectivity will certainly cause counteractive to individuals in the group and the enhancement of group subjectivity is good for development and realization of individual subjectivity in turn.

Historically, in contemporary China of transition, individual and community subjectivity have had a great extent of development and improvement, which laid a necessary prerequisite and basis for shaping a favorable interaction mechanism between individuals and communities. However, we also need to recognize that construction of a good interaction mechanism cannot be achieved in a short time. It is inevitable to be a relatively complex and long process, and may be always accompanied with the process of social transformation.

\subsection{Cultural Choice and Institutional Innovation}

Except subjectivity cultivation and generation, to construct a good interaction mechanism between individuals and groups, there is another theory and practice request, cultural integration and system innovation. Culture and system is the foundation of human existence; they are not only related to individual and community subjectivity, but also related to survival and development of individuals and communities. Therefore, exploring related cultural and institutional factors is bound to research the interaction mechanism between individual and community.

Generally speaking, culture is created by people with subjectivity without whom there can not be culture. In return, culture helps shape and mould people. Therefore, culture must not be separated from people living in it who are the fundamental bearer of culture. To say broadly, contemporary Chinese culture is the mixture of the following culture types and modality, including traditional Chinese culture underpinned by Confucianism, foreign culture that mainly comes from the West, the ideology of Marxism(socialism and communism), etc. In whatever way to classify, there exists multiple cultural factors and types in contemporary China. 
Due to the diversity, discrepancy and complexity of cultural types, cultural conflicts, exchanges, integration and other complex relations arise among every kinds of culture modality. Regard to culture coexistence, some Chinese scholars advocate the principle of "predominance in difference" in which traditional Chinese culture is fundamental, and predominates or absorb reasonable factors of other foreign cultures to form new culture structure; others insist that we should be based on a western culture and take in the rational factors of traditional Chinese culture to face modernization and construct Chinese modern culture. In spite of theoretical and practical significance in certain periods, these arguments are no longer suitable for an increasingly modernized China. On one hand, the belief of "predominance in difference" is good for the settlement of inter-cultural conflicts. On the other hand, it will inevitably do harm to, or even pose a threat to other cultures and individuals they mould and shape. It becomes unsuitable for a modernizing China for it can not provide cultural support accordingly. China's modernization started under constraint, or we can say, the aggression from western powers forces China to kick off its journey towards modernization. Though it is not synonymous with westernization, China's modernization bears deep imprint of western influence. That is to say for, the modernization way taken by the West is partially accepted and adapted by China. The process of modernization includes not only the conflicts between tradition and modernity, but also their integration which generates the seeds of further development. Thus, it can be concluded that traditional elements can serve as the engine of modernization, and western and traditional factors are surely the basic cultural supplier or resource in China's social transformation. For this reason, the way to integrate culture by the principle of "predominance in difference" becomes unsuitable for China's development.

To adapt to Chinese society reality in the process of transformation, the best way to treat contemporary Chinese culture should be the "dynamic equilibrium of diverse cultures", which means not the neck-and-neck development without priority, but make a specific selection and integration mutual infiltrated culture modality according to the specific circumstance of social transformation and development. For example, in the beginning of promoting modernization overall, the major role of western modernity culture should be highlighted, while a variety of other cultures should be taken the secondary and subordinate position in order to encourage individuals to join the modern construction with greater passion, creativity and subjectivity, who have been depressed for a long time. However, during the period of proceeding modernization, the subjectivity and creativity of individual have been fully developed, when Chinese traditional culture should be placed to the important place in the selection and integration of culture modality's selection and integration, and other cultural patterns should be placed in secondary position. Therefore, culture modality's selection and integration is not a wishful thinking by culture creator or subjectivity, but a rational analysis based on social reality is what we need in the process of Chinese modernization.

On the account of the dynamic balance among variety cultural patterns, there are different degrees of confrontation and conflict and of course, where also have exchanges, harmony and integration in different individuals and groups influenced and shaped by different cultures. From the dialectical point of view, opposition and conflict together with unity and harmony are the prerequisite and basis for existence and development of various cultural forms. Moreover, due to the existence of dialectical unity between the various cultural forms, each culture can survive and develop itself. Without contradiction, conflict and communication among cultures, separate culture can't survive and develop. In this way, each kind of culture state or modality can reflect, adjust itself and form a new and more adaptable culture state or type in the contradiction, conflict and communication.

What should be said is that contradiction and conflict are the prerequisite for harmonious symbiosis. So we can not deny the possibility of different culture modality or types moving towards harmonious symbiosis because of contradiction and conflict among them. As pointed by Toynbee in A Study of History, we have inadvertently truck ourselves in a new situation where humans may have to make a choice between two extremes: plan to extinct and slaughter, or learn to live like a family. Here "learn to live like a family" means the tendency for future and culture state. Of course, Toynbee's thinking is not limited to a certain region and country but in a more cosmopolitan view. Through investigation, 
we have basically grasped the culture reality in the process of china's modernization in the period of social transformation: the coexistence of multiple cultural forms. The selection and integration of culture must be based on the social reality, and need to adjust accordingly. There is no uniform rules and standards once and for all.

Culture belongs to human and human is key point of culture, so human is an existence of cultural significance. Culture will shape people from both material level and spiritual. However, in contemporary China of social transformation, culture needs to be re-selected and constructed, not yet completed. In this case, culture's shaping manifests some disorder or clutter. What's more, culture itself is a flexible and soft power, which means that it is difficult to truly play the role it should play by depending on culture only, especially to shape individuals and groups from inner spiritual. A rigid and special system is required to work with flexible culture for a combined effect to individuals and communities in transformation society, and thus laid the foundation for a positive interaction mechanism between individuals and communities.

The same with culture, system is widespread as a universal phenomenon in all areas of social life. It has been an important concept in political science or sociology. The system is made according to specific historical conditions; its formation is used to regulate human behavior. Generally, system is a certain group of rules regulating human behaviors, such as political system, economic system, legal system, education system, religious system, marriage and family system and so on. Political system is in a core position within the organism formed by the other systems, and it can plan the institutional framework of the whole society by using its power. The same with culture, human is the key point of social system. Different from flexible mechanisms of culture, system posed much more rigidity to human in constraints or normative roles.

In the period of social transformation of contemporary China, various rules and systems are in the process of re-construction and generation to maintain the modernization. To some extent, the design or arrangement of system is an important sign to evaluate the political civilization of a modern society. In order to reduce or avoid the system absence, rigidity, malfunction and so on, the government should take necessary and timely actions to make, adjust, reform and innovate. In this way, we can regulate the individuals and groups with the powerful force of systems in real life, which is more important and urgent. And it certainly requires a relatively long period of time. Institutional factors are indispensable in proceeding China's modernization and building benign interaction mechanism between individuals and groups. Indeed, it is more important than the role of culture in some degrees.

\section{Conclusion}

In contemporary China of social transformation, systems which are necessary to maintain modernization are in a process of re-structure and re-generation. To some degree, system design or system arrangement is an important symbol to assess modern social political civilization. In order to reduce or avoid system defect, system sclerosis, and system failure, government should make necessary and timely development, adjustment, reform and innovation to its systems according to specific reality of social development. Thus, system becomes a relatively rigid strength to restrict individuals and communities in real life; and this is more important and urgent in contemporary China. That will be a relatively long process. In order to promote China's modernization process, to build a positive interaction mechanism between individuals and communities, institutional factors is indispensable, even more important than the role of culture in a certain sense.

\section{Acknowledgments}

Collaborative Innovation Center of Beijing College about Chinese characteristics socialism research (Capital Normal University) Marxism and Contemporary Chinese Literature Construction Project (PXM2016_014203_000107). 


\section{References}

[1] Xiaohong, Z.2004, The Transition of the Conception of Individual: An Important Issue in Studies on China's Modernity. Shanghai: Journal of East China Normal University (Philosophy and Social Sciences) .

[2] Zhang, G.2002, Philosophy of Subjectivity. Kunming: Yunnan People's Publishing Press.

[3] Yaohuai,L.1997,Deviance Theory: Cultural Analysis of Social Abnormal Behavior. Changsha: Central South University of Technology Press.

[4] Su,G. The Disputes Between Liberalism and Communitarianism. Nanjing: Journal of Nanjing University (Philosophy, Humanities and Social Sciences).

[5] John Rawls. 1993, Political Liberalism. New York: Columbia University Press.

[6] Markate Daly. 1994, Communitarianism: A New Public Ethics. California: Wadsworth Publishing Company.

[7] Michael Sandel. 1982,Liberalism and the Limits of Justice. Cambridge University Press.

[8] Marx and Engels. 1965, Complete Works of Marx and Engels, Vol. 3, Beijing: People's Publishing Press. 